Bangladesh Journal of Neuroscience 2008; Vol. 24 (1) : 34-44

\title{
Role of Electro-Diagnostic Tests In Early Detection of Diabetic Neuropathy
}

\author{
ZAHED ALI $^{1}$, MALIHA HAKIM ${ }^{1}$, MONIRUL ISLAM ${ }^{2}$, NIRMALENDU BIKASH

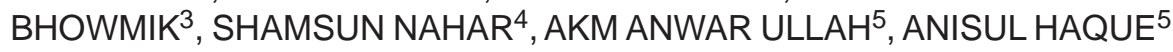

\begin{abstract}
Abstact:
Since the peripheral nerve has the ability to regenerate, therapeutic intervention at earlier stages expected to have a better result in the treatment of diabetic neuropathy. So early detection of diabetic neuropathy is one of the major goals in its management.
\end{abstract}

Purpose: The purpose of present study is to evaluate the efficacy of the electrodiagnostic tests to detect diabetic neuropathy at an early stage (before development of the signs of neuropathy).

Method: 30 diabetic patients with or without symptoms of diabetic neuropathy were included in the test group. Diabetic patients with signs of neuropathy and with other complications, like stroke, peripheral vascular diseases were excluded. Twenty six control subjects (non-diabetic with no family history of diabetes) were included. Both the groups were matched for age. To see the functional status of peripheral nerves motor nerve conduction velocity (NCV), compound muscle action potentials (CAMP) of median nerve were studied. Sensory nerve conduction velocities (NCV), and sensory nerve action potential (SNAP) of median and sural nerves were also measured.
Results: Sensory nerve conduction velocity of sural nerve was significantly slowed $(43.84 \pm 8.23$ vs $48.23 \pm 5.03 \mathrm{~m} / \mathrm{sec}, p<.05)$ in diabetic patients. Sural sensory nerve action potential has lower in amplitude $(13.31 \pm 7.03$ vs $14.24 \pm 4.714 \mathrm{mv}, p<.3)$ in diabetic patients. Median sensory nerve conduction velocity did show difference $(50.89 \pm 8.23$ vs $57.17 \pm 6.67 \mathrm{~m} / \mathrm{s}, p<.01)$ and median sensory nerve action potential has significantly lower in amplitude

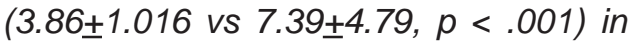
diabetic patients.

No significant difference was found in median nerve motor conduction velocity between the two groups of subjects. Amplitude of compound muscle action potential of median nerve also shows no significant variations.Considering mean $\pm S D$ value of conduction parameter as the cut off value, sural nerve sensory conduction velocity was found slowed in 8 diabetic subjects (26\%).

Sural nerve sensory action potential was of lower amplitude in 12 diabetic subjects (40\%). Eleven diabetic subjects (36\%) had lower amplitude for median sensory nerve action potential (SNAP). For compound muscle action potential (CAMP) and sensory nerve action potential (SNAP) half

1. Department of Neurology, Sir Salimullah Medical College, Dhaka.

2. Department of Physical Medicine and Rehabilitation, National Institute of Traumatology, Orthopaedics \& Rehabilitation (NITOR), Dhaka.

3. Department of Neurology, BIRDEM Hospital \& Ibrahim Medical College, Dhaka.

4. Department of Physical Medicine and Rehabilitation, Bangabandhu Sheikh Mujib Medical University, Dhaka

5. Department of Neurology, Bangabandhu Sheikh Mujib Medical University (BSMMU), Dhaka. 
the mean value of control was the cut off point.

Conclusion: The result suggests that in diabetic patients of Bangladesh with or without symptoms of neuropathy, abnormalities of nerve conduction parameters can be detected early by routine electrodiagnostic monitoring. Sensory nerve conduction parameters are affected more than motor ones. Amplitude abnormalities are slightly more common than conduction velocity or latency abnormalities for sensory studies. Lower extremity nerves were affected more. Sural median nerve has the highest abnormalities in diabetic patients with early neuropathy.

\section{Introduction}

Diabetic neuropathy is peripheral somatic and/or autonomic nerve damage attributable solely to diabetes mellitus (Consensus statement, American Diabetic Association, 1995). It may be associated both with considerable morbidity and mortality. Diabetic neuropathy is characterized by striking atrophy and loss of myelinated and unmyelinated fibres accompanied by Wallerian degeneration, segmental and paranodal demyelination and blunted nerve fibre regeneration. In type 1 and in type 2 diabetes major observation is that of Wallerian degeneration, which may be patchy and irregular ${ }^{1}$.

Nerve conduction studies are considered to be the most sensitive reliable noninvasive and objective means of investigating diabetic polyneuropathy. They involve stimulation of either motor or sensory nerves with subsequent recording of either a sensory or a compound motor action potential. Evaluation of several parameters, including latency, conduction velocity and amplitude is helpful in determining the types of fibre involvement. Analysis of action potential amplitude allows estimates of the total number of active fibres. Conduction velocity provides a measure of transmission in largest myelinated fibres.

NCVs in subclinical group have mean values $10-30 \%$ below the normal. Reduction of amplitude also is found particularly in sensory nerves. Lower extremity distal nerves in particular sural nerves, frequently show the most significant abnormalities. Studies of proximal nerve function, such as F-wave testing may show changes as well. The presence of fibrillation potentials on EMG especially in intrinsic foot muscles also may be found. Once symptoms develop, electrophysiological testing reveals even more significant abnormalities of both sensory and motor nerves than is found in asymptomatic patients.

A study among asymptomatic and symptomatic diabetic neuropathic patients has found strong correlation between myelinated fibre density and sural nerve sensory conduction velocity, sural action potential amplitude, peroneal motor conduction velocity and median sensory amplitude, whereas no corelation existed between myelinated fibre density and median MCV or median sensory conduction velocity. Sural sensory conduction velocity (SCV) was abnormal in $66 \%$ of patients, sural sensory action potential amplitude (SAP) in 40\%, median MCV in $40 \%$, median SCV in $53 \%$ and median SAP in $47 \%^{2}$.

Another nerve condition studies among early diabetic neuropathic patients observed that approximately $21 \%$ had both 
normal peroneal and sural examinations. Abnormalities were most common in sural conduction studies ( $68 \%$ right and $67 \%$ left), followed in descending frequency by median sensory (60\%), peroneal (46\%) and median motor (36\%) recordings. Amplitude abnormalities were slightly more common than conduction velocity or latency abnormalities for sensory studies, whereas conduction velocity abnormalities exceeded latency or amplitude abnormalities for motor studies. These diabetic patients had sensory amplitudes 10-15 mv lower and conduction velocities 4 to $14 \mathrm{~m} / \mathrm{sec}$ slower than normal subjects. Deviations from normal were greater in the lower than in the upper extremities; sural measures demonstrated the largest deviation from normal, and median sensory measures demonstrated the smallest deviations from normal ${ }^{3}$. This study recognized the neuropathy as mild when sural or peroneal responses were obtainable.

Motor conduction studies in different series in any or all of the following nerves-median, ulnar, peroneal and tibial nerves showed increase in distal latency, amplitude reduction of compound muscle action potential (CMAP) and slowing of motor conduction velocity. Latency to extensor digitorum bravis and abductor hallucis may be increased by 28 to $39 \%$, the CMAP amplitude reduced by 50 to $80 \%$ and the conduction velocity reduced by 28 to $39 \%$ compared with normal mean values for the respective parameters.

Sensory conduction in diabetic patients was studied by using near nerve electrode. The average sensory conduction velocity (SCV) was reduced by $37 \%$, the SAP amplitude by $40-92 \%$ compared with the normal mean value. In all the patients the SCV and SAP amplitude were below the normal mean, and in most, also below the 95\% lower limit of normal.

A comparison of abnormalities in IDDM and non-IDDM patients without neuropathy revealed abnormal sensory function in the sural nerve in $76 \%$ and $64 \%$ respectively. In the median sensory conduction velocity abnormalities occur in $3 \%$ cases $^{4}$. Abnormalities of nerve conduction parameters are the early features of diabetic nerve damage ${ }^{5}$ which signifies that neurological techniques and prevalence of peripheral neuropathy are specific to the population tested. So, it is important to study nerve conduction parameters in different racial groups taking into consideration that various factors may influence the parameters.

Since peripheral nerve has the ability to regenerate it has been proposed that therapeutic intervention including improvement of blood glucose control, aldose reductase inhibitors, and gangliosides may prove efficacious in the treatment of diabetic neuropathy. Studies of potential therapies in patients with established often severe neuropathies have demonstrated slight improvement in nerve function. Intervention in earlier stages may be more successful ${ }^{2}$. In the above context the present study has been designed to see the measures of peripheral nerve function in mild diabetic neuropathies in diabetic population of Bangladesh and to see the early changes of nerve conduction parameters in diabetic patients.

\section{Aims and Objectives}

1. To see the functional status of the peripheral nerves among Bangladeshi 
diabetic subjects by electrodiagnosis (NCV).

2. To see the early changes of nerve conduction parameters in diabetic patients.

\section{Subjects and Methods}

\section{Subjects}

This study was carried out in the Department of Neurology, Bangabandhu Sheikh Mujib Medical University (BSMMU) and Department of Neurology, Bangladesh Institute of Research and Rehabilitation in Diabetes, Endocrine and Metabolic Disorders (BIRDEM), Dhaka, Bangladesh, during the period of January 2000 to June 2001.

A total number of 56 patients were included in this study. Out of which 30 were diabetic and 26 were control.

\section{Healthy controls}

Total number of control subjects was 26 (male 15, female 11). These healthy volunteers with mean age comparable to that of diabetic subjects were selected from the friends of the patients attending neurology outdoor, BSMMU, Dhaka.

All the volunteers were apparently healthy as assessed by detailed medical history and clinical examinations. None of them had history of diabetes.

\section{Diabetic subjects}

Thirty known diabetic patients (male $=18$, female $=12$ ) attending at the out-patients department of BIRDEM were included. WHO criteria were followed for the diagnosis of diabetes mellitus.

\section{Inclusion criteria}

1. Patients of diabetes mellitus of any duration.

2. Diabetic subjects with no symptoms and signs of neuropathy.

3. Diabetic subjects with sensory symptoms only (i.e. numbness, tingling, pain, hypersensitivity to touch).

4. Diabetic subjects with sensory symptoms and sensory signs (i.e. impairment of touch, pain and vibration sensation).

\section{Exclusion criteria}

1. Diabetic subjects who had diabetic complications, like stroke and overt nephropathy detected by proteinuria.

2. Patients of DM with foot ulcers and/ or charcot joints.

3. Pregnancy.

4. Subjects with acute or chronic systemic illness, skin infection detected clinically and routine biochemical examination, e.g. TC, DC, ESR, SGPT, Blood urea, S. Creatinine, Urine R/M/E.

\section{Observation and Results}

Age and Sex of the study groups:

\section{Control group}

Twenty-six healthy controls, 15 males and 11 females were included in the study (Table-I). Age in years (mean $\pm \mathrm{SD}$ ) was 54.8+13.56 (Table-II).

Table I

Sex distribution of the study subjects

\begin{tabular}{lccccc}
\hline Groups & \multicolumn{2}{c}{ Male } & & \multicolumn{2}{c}{ Female } \\
\cline { 2 - 3 } \cline { 5 - 6 } & Number & $\%$ & & Number & $\%$ \\
\hline Control $(n=26)$ & 15 & 57.69 & & 11 & 42.31 \\
Diabetic $(n=30)$ & 18 & 60.00 & & 12 & 40.00 \\
\hline
\end{tabular}




\section{Diabetic group}

Thirty-six diabetic subjects participated in this study. Among them 18 were males and 12 were females (Table-I). Mean ( \pm SD) age was $56.77 \pm 11.83$ years (Table-II).

\section{Table-II}

Age of the study subjects

\begin{tabular}{lc}
\hline Groups & Age (years) \\
\hline Control $(n=26)$ & $54.8 \pm 13.56$ \\
Diabetic $(n=30)$ & $56.77 \pm 11.83$ \\
\hline
\end{tabular}

Nerve conduction parameters of study subjects.

Motor nerve conduction parameters of control group

Median nerve: Median range of compound muscle action potentials was 12.31 (18.618.836) mv. Mean ( $\pm S D)$ median motor conduction velocity was $53.59 \pm 9.65 \mathrm{~m} / \mathrm{sec}$ (Table III).

Table-III

Motor nerve conduction parameter of Median nerve

\begin{tabular}{lcc}
\hline Groups & $\begin{array}{c}\text { MCAMP } \\
(\mathrm{mV})\end{array}$ & $\begin{array}{c}\text { M NCV } \\
(\mathrm{m} / \mathrm{s})\end{array}$ \\
\hline Control $(\mathrm{n}=26)$ & $12.31(18.61-8.84)$ & $53.59 \pm 9.65$ \\
Diabetic $(\mathrm{n}=30)$ & $11.02(17.75-3.47)$ & $50.98 \pm 6.73$ \\
$\mathrm{t}$ & 0.505 & 1.154 \\
$\mathrm{p}$ value & $>0.10$ & $>0.10$ \\
\hline
\end{tabular}

Results have been expressed as mean \pm SD.

For CAMP median range was calculated. Significance of difference at $5 \%$ level of significance between the groups was compared by " $\mathrm{t}$ " test.

MCAMP = Median Compound Muscle Action Potential

MNCV $=$ Median Nerve Conduction Velocity

\section{Diabetic group}

Median nerve: Median range of median nerve compound muscle action potential was 11.02 (17.75-3.47) mv. Value of median nerve conduction velocity (Mean \pm SD) was $50.98 \pm 6.73 \mathrm{~m} / \mathrm{sec}$ (Table-III). No significant variation in nerve conduction velocity of median nerve was found among the groups. Amplitude of compound muscle action potential of median nerve was not significantly changed.

\section{Sensory nerves conduction parameters.}

\section{Control groups}

\section{Median nerve}

Mean $( \pm S D)$ median sensory nerve action potential was $7.39 \pm 4.79$ (Table-IV). Mean $( \pm S D)$ Median nerve conduction velocity was $57.17 \pm 6.67 \mathrm{~m} / \mathrm{s}$ (Table-V).

Table-IV

Comparison between Control and

Diabetic groups for Amplitude of Median

Sensory nerve action potential

\begin{tabular}{lc}
\hline Groups & Amplitude (SNAP)(mV) \\
\hline Control $(n=26)$ & $7.39 \pm 4.79$ \\
Diabetic $(n=30)$ & $3.86 \pm 1.016$ \\
Calculated t value & -4.68 for 54 df \\
p value & $<.001$ \\
\hline
\end{tabular}

Results have been expressed as mean \pm SD.

Significance of difference at $5 \%$ level of significance between the groups was compared by " $\mathrm{t}$ " test.

Table-V

Comparison between Control and

Diabetic group for Sensory Nerve

Conduction Velocity of Median nerve

\begin{tabular}{lc}
\hline Groups & $\begin{array}{c}\text { Conduction velocity } \\
\text { of median sensory }(\mathrm{m} / \mathrm{s})\end{array}$ \\
\hline Control $(\mathrm{n}=26)$ & $57.17 \pm 6.67$ \\
Diabetic $(\mathrm{n}=30)$ & $50.89 \pm 8.28$ \\
Calculated t value & 3.09 for $54 \mathrm{df}$ \\
\hline
\end{tabular}


Sensory nerve: Mean $( \pm S D)$ sural sensory action potential was $14.24 \pm 4.712$ (TableVII). Mean ( \pm SD) sural nerve conduction velocity was $48.23 \pm 5.03 \mathrm{~m} / \mathrm{s}$ (Table-VI).

Table-VI Comparison between Control and Diabetic group for Sensory Nerve Conduction Velocity of Sural nerve

\begin{tabular}{lc}
\hline Groups & $\begin{array}{c}\text { Conduction velocity } \\
\text { of Sural nerve }(\mathrm{m} / \mathrm{s})\end{array}$ \\
\hline Control $(\mathrm{n}=26)$ & $48.23 \pm 5.03$ \\
Diabetic $(\mathrm{n}=30)$ & $43.84 \pm 8.23$ \\
Calculated t value & -2.24 for $54 \mathrm{df}$ \\
p value & $<.05$ \\
\hline
\end{tabular}

Results have been expressed as mean \pm SD.

Significance of difference at $5 \%$ level of significance between the groups was compared by " $\mathrm{t}$ " test.

\section{Diabetic group}

Median nerve: Mean $( \pm S D)$ median sensory nerve action potential was $3.86 \pm 1.016$ (Table-IV). Mean ( $\pm S D$ ) median nerve conduction velocity was $50.89 \pm 8.28$ $\mathrm{m} / \mathrm{sec}$ (Table V).

Sural nerve: Mean ( $\pm S D)$ Sural nerve sensory action potential was $13.31 \pm 7.03$ (Table-VII). Mean ( \pm SD) sural nerve conduction velocity was $43.84 \pm 8.23 \mathrm{~m} / \mathrm{sec}$ (Table VI).

Mean ( \pm SD) of median sensory nerve action potential of median nerve was significantly lower $(p<.001)$ in diabetic group compared to control (Table-IV). Significant difference was found in sensory nerve conduction parameters of median nerve between the two groups (Table-V).

Mean ( $\pm S D$ ) nerve conduction velocity of sural nerve was significantly slower $(p<$
.001) in diabetic group compared to control (Table-VI). Mean ( $\pm S D$ ) of sural nerve sensory action potential was significantly lower in diabetic group $(p<$.001) (TableVII).

Table-VII

Comparison between Control and Diabetic group for Amplitude of Sural nerve

\begin{tabular}{lc}
\hline Groups & $\begin{array}{c}\text { Amplitude of Sural } \\
\text { nerve }(\mathrm{mv})\end{array}$ \\
\hline Control $(\mathrm{n}=26)$ & $14.24 \pm 4.714$ \\
Diabetic $(\mathrm{n}=30)$ & $13.31 \pm 7.03$ \\
Calculated t value & -0.586 for $54 \mathrm{df}$ \\
p value & $<.3$ \\
\hline
\end{tabular}

Significance of difference at $5 \%$ level of significance between the groups was compared by " $\mathrm{t}$ " test.

\section{Discussion}

The present study was undertaken to evaluate the functional status of the peripheral nerves in diabetic subjects of Bangladesh with early diabetic neuropathy by electrodiagnosis and to explore whether any difference exist between the pattern of peripheral nerve involvement in diabetic subjects of Bangladesh and other countries. Data from healthy control subjects have given the idea about the normal range of nerve conduction parameters in this study.

Clinical characteristics of study subjects The healthy controls and diabetic subjects were of comparable age. Among the diabetic and healthy control subjects males predominated over females (Table-I).

Diabetic subjects were patients of diabetes of any duration. Asymptomatic and only symptomatic patients without signs were 
included in the study. Patients with obtainable sural nerve responses were included in this study as recognized the neuropathy as mild when sural and peroneal responses were obtainable ${ }^{3}$. Other causes of sensory-motor neuropathy were excluded by clinical examination and appropriate investigations.

\section{Nerve conduction parameters of study subjects:}

One objective of the study was to see functional status of peripheral nerves in early diabetic neuropathy. We have carried out unilateral studies of motor and sensory conduction of median nerve for upper limbs. Unilateral study of sural nerve was done in lower limbs.

\section{Diabetic vs control subjects:}

No significant variation in median motor nerve conduction velocity and amplitude of compound muscle action potential of median nerve were found among the groups.

But median sensory nerve action potential (SNAP) differed significantly $(p<.001)$ in diabetic subjects having lower amplitudes (Table-IV). Median sensory nerve conduction velocity also showed significant difference among the groups $(p<.01)$.

Sensory nerve conduction velocity of sural nerve was significantly slower $(p<0.05)$ in diabetic group compared to control (Table$\mathrm{VI}$ ). Amplitude of sural nerve sensory action potential diabetic group but Table- $V$ in significant $(P<.3)$.

Most of the sensory nerve conduction parameters tended to differ significantly in diabetic subjects with early diabetic neuropathy from those of control subjects. Among the sensory nerve conduction parameters amplitudes of sensory nerve action potential were affected more than conduction velocity. Motor nerve conduction parameters did not show significant difference among the groups. Previous studies also showed similar pattern of changes in nerve conduction parameters in early diabetic neuropathic patients ${ }^{3,4}$. Prolonged sural sensory conduction velocity and lower amplitude of sural sensory action potential supports distal to proximal gradient of abnormality in diabetic sensory somatic neuropathy 6 .

Among the nerve conduction parameters sural nerve sensory conduction velocity was found slowed in eight diabetic subjects $(26 \%)$, but only 1 control subject had abnormal sural sensory conduction velocity (4\%).

Median sensory nerve conduction velocity was lower in 1 control subject (4\%), whereas it was lower in 7 diabetic subjects (23\%).

Sural nerve sensory action potential was of lower amplitude in 12 diabetic subjects (40\%), 11 diabetic subjects had lower amplitude for median sensory nerve action potential (SNAP) (36\%).

But compound muscle action potential (CMAP) of median nerve was of lower amplitude in one diabetic subjects (3\%).Five diabetic subjects have normal median motor nerve conduction velocity (16\%).

Mean $\pm S D$ value of the conduction parameters can be considered as the cut off value. For compound muscle action potential (CAMP) and sensory nerve action potential (SANP) half the mean value of control was the cut off point? .

But in a previous study ${ }^{3}$, showed the disease duration and anthropometric 
factors on nerve conduction measures in mild diabetic neuropathy. They evaluated nerve conduction measures of 429 early diabetic patient of which 162 were type II diabetic patient. This study showed that abnormalities were most common in sural conduction studies (68\% right and $62 \%$ left) followed in descending order of frequency by median sensory (60\%), peroneal (46\%) and median motor recordings. But our studies show involvement in less percentage of diabetic patients. This probably reflects different patterns of involvement in nerve conduction measures in type I diabetes mellitus.

Also showed that compared with female patients, male patients had significantly lower amplitudes and conduction velocities and longer latencies ${ }^{3}$. This effect was greatly reduced when height was included in regression model although gender continued to be a significant predictor of median sensory amplitude and most conduction velocities and latencies. Inclusion of greater number of female patients in our early diabetic group may be responsible for less frequent abnormalities in nerve conduction measures in diabetic patients.

In another study ${ }^{\mathbf{8}}$, the investigators chose the sural nerve to examine the possible effects of age, gender and height on conduction velocity (CV) and nerve action potentials (NAP) amplitude. Despite a linear decrease in MCV and SCV or both with increasing age, in order of 0.5 to 1.8 $\mathrm{m} / \mathrm{s}$ per 10 years has been described by some reports, this study showed that when variations in $\mathrm{CV}$ due to linear relation with height is removed, the age is not related to sural nerve CV. In fact the decrease with increasing age was found to be minimal $(0.09 \mathrm{~m} / \mathrm{s}$ per year), other reports supported this by denying any relation within age ranges from 6 to 84 years in nerves of upper and lower limbs. The CV decreases 0.15 $\mathrm{m} / \mathrm{s}$ per $100 \mathrm{~mm}$ increase in heights. When considering 37 individuals aged $25-34$ years only, CV increased $0.34 \mathrm{~m} / \mathrm{s}$ per 1 meter increase in height. In both instances, the changes were within the experimental error of the method. This study also found slightly higher average amplitude of the NAP in females than males. So far an acceptable explanation for this has not been suggested although improved conduction properties due to thicker layer of subcutaneous fat in women could be the reason.

So, it can be presumed that age did not significantly influence the nerve conduction parameters in our study subjects but gender and height have some influence. Nerve conduction parameters may be also influenced by factors, such as room and muscle temperatures, duration of diabetes, glycaemic control and peripheral blood flow $^{2}$. All of above factors may be responsible for the difference of nerve conduction parameters in early diabetic patients in our study and previous studies.

Comparison of the results of our study with those from previous reports is difficult also because of different methods and patient selection criteria. Nevertheless, our study showed that sural sensory conduction velocity, and median sensory amplitudes are the sensitive indicators of early diabetic neuropathy though occurring in less number of patients and sural nerve has the highest abnormalities. Prolonged sural sensory nerve conduction velocity supports distal to proximal gradient of 
abnormality in diabetic sensory somatic neuropathy ${ }^{6}$.

\section{Conclusions}

1. Abnormalities of nerve conduction parameters are detected early in diabetic subjects of Bangladesh.

2. Sensory nerve conduction parameters are affected more than motor ones.

3. Formal conduction velocities or latency abnormalities for in in sensory studies.

4. Sural nerve has the highest abnormalities in diabetic patients with early neuropathy.

5. This study has been carried out in a small group of diabetic population. Further broad based study is required to see the effect of race, ethnicity and anthropometry on nerve conduction measures.

\section{Recommendations}

Diabetic patients should be routinely monitored by the electrodiagnostic test for early detection of neuropathy.

\section{References:}

1. Sima AAF, Thomas PK, Ishii D, Vinik A. Diabetic neuropathy. Diabetologia 1997; 40(Suppl.3): B74-B77.

2. Veves A, Malik RA, Lye RH, Masson EA, Sharma AK, Schady W, et al. The relationship between sural nerve morphometric findings and measures of peripheral nerve function in mild diabetic neuropathy. Diabetic Med 1991; 8: 917-21.

3. Albers JW, Brown MB, Sima AAD, Green DA. Nerve conduction measures in mild diabetic neuropathy in the early diabetes intervention trait: the effect of age, sex, type of diabetes, disease duration and anthropometric factors. Neurology 1996; 46: 85-91.

4. Trojaborg W. The electrophysiological profile of diabetic neuropathy. Seminars Neurology 1996; 16: 12328.

5. Clarke BF, Ewing DJ, and Campbell IWQ. Review Article: diabetic autonomic neuropathy. Diabetologia 1979; 17: 195-212.

7. Kimura J. Electrodiagnosis in Diseases of nerve and muscle: Principle and Practice. $2^{\text {nd }}$ ed. Philadelphia: FA Dan's Company; 1989. pp.103-08.

8. Trojaborg WT, Moon A, Andersen BB, Trojaborg NS. Sural nerve conduction parameters in normal subjects related to age, gender, temperature and height: a reappraisal. Muscle Nerve 1992; 15: 666-71.

9. Bay HE, and Pfeifer MA. Peripheral diabetic neuropathy. Med Clin North Am 1988; 72: 1439-65.

10. Burgstrom B, Lilja B, Osterlin S. Autonomic neuropathy in non-insulin dependent (Type II) diabetes mellitus. Possible influence of obesity. J Intern Med 1990; 227: 57-63.

11. Boulton AJM, Knight G, Drury J, Ward JD. The prevalence of symptomatic diabetic neuropathy in an insulintreated population. Diabetes Care 1985; 8: 125-28.

12. Cameron NE, Cotter MA. Metabolic and vascular factors in the 
pathogenesis of diabetic neuropathy. Diabetes 1997; 46 (Suppl.2): S31S37.

13. Standardized measures in diabetic neuropathy (Consensus statement). Diabetes Care 1995; 18 (Suppl. 1): 5964.

14. John C, and Williams, G. Clinical features of diabetic neuropathy. In: Pickup JC and Williams G, editors. Textbook of Diabetes, $2^{\text {nd }}$ edn. Oxford: Blackwell Science. 1997; pp 1-59.

15. Watkins PJ, Edmonds ME. Clinical features of diabetic neuropathy. In: Pickup JC, and Williams G, editors. Textbook of diabetes. $2^{\text {nd }}$ ed. Oxford: Blackwell Science.1997; pp 50.150.20 ,

16. Diabetic Neuropathy (Consensus statement). Diabetes Care 1995; 18(Suppl. 1): 53-58.

17. Drybert T, Bern J, Christiansen JS, Hilsted J. Prevalence of autonomic neuropathy measured by simple bedside tests. Diabetologia 1981; 20: 190-94.

18. Greene DA, Sima AAF, Feldman EL, Lattimer SA. Complications: neuropathy, pathogenetic considerations. Diabetes Care 1992; 15: $1902-25$

19. Harati Y. Diabetic peripheral neuropathy. Ann Intern Med 1987; 107: 546-59

20. Jensen $\mathrm{T}$, Feldt-Rasmussen BO, Bjene-Knudsen J, Decker T. Features of endothelial dysfunction in early diabetic neuropathy. Lancet 1989; 1(8634): 461-63.
21. Johnson PJ, Doll SC, Cromey DM. Pathogenesis of diabetic neuropathy. Ann Neurol 1986;19: 450--57.

22. Kesseler L, Weisel ML, Attali P, Mossard JM, Cazener JP, Pinget M, et al. Von Willibrand factor Diabetic Angiopathy. Diabetes Metab 1998; 24: 327-36.

23. Malik RA. The pathology of human diabetic neuropathy. Diabetes 1997; 46(Suppl. 2): S50-S53.

24. Malik RA, Tesfaye S, Thompson SD, Veves A, Sharma AK, Boulton AJM, et al. Endothelial localization of microvascular damage in human diabetic neuropathy. Diabetologia 1993; 36: 454--59.

25. McDonald JWD, Dupre J, Rodgen NW. Comparison of platelet thromboxane synthesis in diabetic patients on correctional insulin therapy and continuous insulin infusions. Thromb Res 1982; 28: 705--12.

26. Newrick PG, Malik RA, Sharma AK, Jennings A, Ah-See AK, Mayhew TM, et al. Microangiopathy in human diabetic neuropathy: relationship between capillary abnormalities and severity of neuropathy. Diabetologia 1989; 32: 92-102.

27. Pathan F. Clinical profile of under-30 diabetic subjects of Bangladesh. [MD (EM) Thesis] Dhaka: University of Dhaka; 1993.

28. Word JD, Tesfaye S. Pathogenesis and clinical features of diabetic neuropathy. In: Pickup JC, and Williams G, editors. Textbook of diabetes. $2^{\text {nd }}$ ed. Oxford: Blackwell Science; 1997. p. 49.1-49.19. 
29. Plater ME, Ford I, Dent MT, Preston FE, Ward JD. Elevated von Willibrand factor antigen predicts deterioration in diabetic peripheral nerve function. Diabetologia 1996; 39: 336-43.

30. Porta M, Salva ML, Molinatti $P$, Molinatti GM. Endothelial cell function in diabetic microangiopathy. Diabetologia 1987; 30: 601-09.

31. Poston L, Taylor PD. Endotheliummediated vascular function in insulin dependent diabetes mellitus. Clin Sci 1995, 88: 245-55.

32. Schror K. Blood vessel wall interactions in diabetes. Diabetes 1997; 46(Suppl. 2): 5115-18.

33. Takahashi K, Ghatei MA, Lam HC, Halloran DJO, Bloom SR. Elevated plasma endothelin in patients with diabetes mellitus. Diabetologia 1990; 33: 306-10.

34. Timperely WR, Ward JD, Prerton FE. Clinical and histological studies in diabetic neuropathy: a reassessment of vascular factors in relation to intravascular coagulation. Diabetoloqia 1979: 12: 237-43.

35. Turk Z. Advanced glycation toxicity and diabetic complications. Diabetologia Croatica 1997; 26: 11-16.

36. Veglio M, Carpano-Maglioli P, Tonda L, Quadri R, Giannella R, Roas C, et al. Autonomic neuropathy in noninsulin dependent diabetic patients: correlation with age, sex, duration and metabolic control of diabetes. Diabetes Metab 1990; 16: 200-06.

37. Vinik Al, Holland MT, Le Beua JM, Li'uzzi FJ, Stansberry KB, Colen LB. Diabetic neuropathies. Diabetes Care 1992; 15: 1926-51.

38. Young RJ, Ewing DG, Clarke BF. Nerve function and metabolic control in teen-age diabetics. Diabetes 1983; 32: $142-47$. 